\title{
A Survey Based Analysis of IT Adoption and 3PLs' Performance
}

\begin{abstract}
Purpose - In today's competitive scenario, effective supply chain management is increasingly dependant on third party logistics (3PL) companies' capabilities and performance. The dissemination of information technology (IT) has contributed to change the supply chain role of 3PL companies and IT is considered an important element influencing performance of modern logistics companies. Therefore, the purpose of this paper is to explore the relationship between IT and 3PLs' performance, assuming that logistics capabilities play a mediating role in this relationship.
\end{abstract}

Design/methodology/approach - Empirical evidence based on a questionnaire survey conducted on a sample of logistics service companies operating in the Italian market was used to test a conceptual resource based view (RBV) framework linking IT adoption, logistics capabilities and firm performance. Factor analysis and ordinary least square (OLS) regression analysis have been used to test hypotheses. The focus of the paper is multidisciplinary in nature; management of information systems, strategy, logistics and supply chain management approaches have been combined in the analysis.

Findings - The results indicate strong relationships among data gathering technologies, transactional capabilities and firm performance, in terms of both efficiency and effectiveness. Moreover, a positive correlation between enterprise information technologies and 3PL financial performance has been found.

Originality/value - The paper successfully uses the concept of logistics capabilities as mediating factor between IT adoption and firm performance. Objective measures have been proposed for IT adoption and logistics capabilities. Direct and indirect relationships among variables have been successfully tested.

Keywords: IT adoption, Italian 3PL industry, logistics capabilities, firm performance, factor analysis, regression analysis.

Paper type: Research paper. 


\section{Introduction}

In recent years the growth in the dissemination of information technology (IT) has radically changed the competitive scenario of modern supply chains (Poirier and Bauer, 2000). A thorough analysis of IT adoption in supply chains must include third-party logistics service providers (3PLs). In fact, the high level of outsourcing of logistics activities has entrusted these specialised actors with the task of integrating and accelerating physical and information flows at multiple levels of the supply chain (Gustin et al., 1995; Cooper et al., 1998; Ojala et al., 2006). The evolution of 3PLs' role, beyond the dyadic relationship with clients, has also emphasised the need to measure their performance, which directly impacts the performance of the supply chain as a whole (Van Hoek, 2002).

Despite IT being an increasingly important element of the logistics service business, little study has been conducted on assessing the impact of technology on performance in 3PL research. In fact, there is the need to increase research in this area as stated by Selviaridis and Spring (2007) in their recent 3PL literature review. This paper is aimed at filling this void by investigating the relationship between IT adoption and 3PLs' performance. Drawing on the resource based view (RBV) approach, logistics capabilities has been considered the mediating variables in this relationship. The research questions addressed are: what is the impact of IT on the performance of logistics service companies; and what is the role of logistics capabilities in this process? To answer the above research questions a questionnaire survey has been carried out involving 153 small and medium Italian logistics service providers.

The main contribution of the paper is twofold. First, the proposed model measures variables in an objective way (e.g. specific technologies are used to measure IT adoption while logistics services provided are used to measure logistics capabilities) in comparison with previous studies that measured these variables predominantly on the basis of subjective judgment. Second, the survey results show that a positive correlation between enterprise information technologies and 3PLs' financial performance has been found. In addition, data gathering technologies impact 3PLs' efficiency and effectiveness performance directly and indirectly, partially mediated by logistics transactional capabilities. In the knowledge of the authors, this is the first study in the logistics and supply chain management field that identifies a positive effect of a mediating variable between IT adoption and firm performance. 


\section{Theoretical development}

\subsection{Research framework and variable definitions}

In the present study, we propose a theoretical framework for the adoption of information technology in logistics providers, based on the resource based view (RBV) theory. RBV suggests that a competitive advantage comes from possessing valuable and rare resources that competitors cannot easily acquire or reproduce (Barney, 1991). 3PLs' processes are extremely diverse spanning from domestic distribution to global shipping and vary across different companies.

Therefore, technologies need to be tailored to firm specific 3PLs' processes. As confirmed by extant literature (Calder and Marr, 1998; James et al., 2006; Lau et al., 2006; Chow et al., 2007) embedding IT in logistics and supply chain processes represents, per se, a part of 3PLs' resource portfolio that can lead to competitive advantage. Therefore we propose that IT adoption has a direct impact on firm performance. Nevertheless, due to the rapid diffusion of innovation, ITbased advantage may diminish fairly quickly (Wu et al., 2006). In fact, empirical research trying to support the positive correlation between IT expenditure and firm performance, has often revealed mix results, a phenomenon known as 'productivity paradox' of IT adoption (Brown et al., 2003). Therefore, we further suggest that the adoption of technologies by 3PLs facilitate the development of organisational factors that we call 'logistics capabilities' that can also be considered as a resource of sustained competitive advantage for a firm. This approach is consistent with the RBV and the theoretical contributions offered by Prahalad and Hamel (1989 and 1994) and Porter (2001). In fact, these authors argue that IT expenditure should not be considered alone, but together with specific organisational or strategic factors. IT expenditure can improve those factors, which can ultimately lead the company to superior performance.

IT adoption is defined as the extent to which a firm embeds a certain set of technologies in its processes and makes them fully operational for being used, as in Li et al. (2009). IT adoption can, therefore, be considered as a resource since, in our definition, we already take into account the development of the technologies and the process redesign performed to embed technologies into company processes.

In the present study, firm performance includes marketing, financial and operational performance, consistently with several studies in the supply chain management field (e.g. Wu et al., 2006; Sanders 2007 and 2008). 
Logistics capabilities refer to the ability of an organisation to perform logistics tasks that facilitate supply chain activities. Our definition of logistics capabilities tries to shed new light on the use of this variable, which has been defined in disparate ways in the extant literature. In fact, previous studies define logistics capabilities in terms of operational performance (Morash et al., 1996; Fawcett et al., 1997; Cho et al., 2008), information capabilities (Shang and Marlow, 2005), or a mix of both these factors (Zhao et al., 2001; Lu and Yang, 2006). These definitions cannot all be used in this work since they overlap with either the IT adoption variable or the firm performance variable. We, therefore, base our definition of capabilities on the strategic management literature, especially on the work of Grant (1991), who defines capabilities as "...the capacity for a team or resources to perform some task or activity" and Sheehan and Foss (2007) who refer to capabilities as “...the ability to execute”. Our definition of logistics capabilities is also consistent with the definition of supply chain capabilities. In fact, Wu et al. (2006) define supply chain capabilities as “...the ability of an organisation to identify, utilise and assimilate both internal and external resources/information to facilitate the entire supply chain activities". Moreover, if we consider logistics as a part of supply chain management, in the so called 'traditionalist approach' (Larson and Halldorsson, 2004) we can argue that supply chain capabilities encompass the smaller set of logistics capabilities. In fact, supply chain capabilities include several concepts, spanning from inter-organisational (or supply chain) integration (Kim, 2006; Rai et al., 2006; Ward and Zhou, 2006; Devaraj et al., 2007; Li et al., 2009), to coordination (Prater and Ghosh, 2006; Sanders, 2008) and collaboration (Yusuf et al., 2004; Lin and Tseng, 2006; Sanders, 2007; Kisperska-Moron and Swierczek, 2008). Moreover, we further identify the logistics tasks cited in our definition as the services offered by 3PLs. The general body of literature on logistics services (Bradley, 1994; Sum and Teo, 1999, Panayides, 2004, Gopal and Cline, 2007) confirms our assumption. Moreover, the few studies focused on this specific issue explicitly draw a clear connection between services and capabilities both in the logistics (Lynch et al., 2000) and supply chain management field (Tracey et al., 2005). Although logistics tasks may not be limited to the logistics services offered by 3PLs to the market, this connection allows us to measure logistics capabilities in an objective way.

The model also incorporates the following four control variables: age of the company, geographical reach, size of the company and customer concentration. They are used to discount rival hypotheses and this is consistent with previous studies in the logistics and supply chain 
management field. These variables are included in the analysis since we believe that they might have influences on logistics capabilities and firm performance. Nevertheless, we are not trying to develop theory related to these variables and thus we do not propose hypotheses related to their effects. The age of the companies is strictly related to their experience of the logistics market which, in turn, can help 3PLs to achieve better performance (Lai et al., 2008). The ability of companies to manage global supply chain operations can be positively correlated to the achievement of competitive advantage. Larger logistics providers might successfully develop economy of scale and scope in their operations, therefore achieving better performance especially in terms of efficiency (Sum and Teo, 1999; Hertz and Alfredsson, 2003; Panayides, 2004; Pearcy and Giunipero, 2008). High values of customer concentration increase the financial risks faced by the 3PLs. This, in turn, might have a negative effect on firm performance.

\subsection{Hypotheses development}

Extant literature suggests that IT adoption positively affects 3PLs' performance. In particular, several studies indicate that the enhancement of customer service and increased productivity and process quality is dependant on IT adoption (Bowersox and Daugherty, 1995; Calder and Marr, 1998; James et al., 2004; Lau et al., 2006, Chow et al., 2007; Liu et al., 2010). The high IT spend of logistics providers is usually triggered by specific requests from customers, who are aware that increased 3PLs' performance, as a result of IT adoption, will benefit the logistics performance of the entire supply chain (Capgemini, 2007). The degree of IT advancement of logistics providers (also in terms of their capability of integration with customer information systems) thus comes into play as an important factor for supplier selection (Lewis and Talalayevsky, 2000; Sauvage, 2003; Hong et al., 2010). This means that turnover improvements in these companies may be partially explained on the basis of their technological advancement (Norek and Langley, 2007). Wang et al. (2008) successfully link 3PL financial performance to IT advantage and IT involvement. A positive relationship between IT adoption and company performance has been found by a recent study conducted on the transport and logistics service sector in the EU (e-Business Watch, 2008, p.144). This study ascertained that 3PL companies that have introduced IT-enabled innovations were more likely to experience sales growth and an increased market share. These arguments collectively suggest the development of our first research hypothesis: 


\section{$H_{I}$ IT adoption has a positive impact on 3PLs' performance.}

Closs et al. (1996) and Piplani et al. (2004) suggest that the adoption of information technologies by 3PLs enable them to acquire specific knowledge and skills that are core to their business. Lai (2004) suggests that the skills acquired via technological innovation are employed by 3PLs to offer a set of services to their clients. Evangelista and Sweeney (2006) also identify information technologies as an enabler for developing logistics capabilities that 3PLs can directly offer to the market via the provision of value added services. Moreover, Lai et al. (2006) and Lai et al. (2008) found a positive correlation between the IT capability of 3PLs and the provision of innovative and customised services.

This rationale leads to our second research hypothesis:

$H_{2}$ IT adoption has a positive impact on 3PLs' logistics capabilities.

The development of logistics capabilities and their exploitation in the market via the provision of services plays a central role in the evolution of logistics providers. Logistics outsourcing started with services (e.g. transportation and warehousing) that were seen by enterprises as non-core and easily available in the market (Sink and Langley, 1997). The external companies taking over these activities, i.e. third-party logistics providers, could then achieve economy of scale and scope by consolidating orders and requests across different customers (Ackerman, 1989; Mentzer and Firman, 1994). Nevertheless, in order to avoid purely cost based competition, 3PLs started to develop their capabilities in order to offer a broader set of services, such as distribution management, third-party inventory management, assembly, etc. (Bradley, 1994; Sum and Teo, 1999, Panayides, 2004, Gopal and Cline, 2007). Acquiring new logistics capabilities allowed 3PLs to expand their offerings from standardised services to customised solutions tailored on customer needs (Razzaque and Sheng, 1998, Delfmann et al., 2002). From a strategic perspective, this has led to a differentiation of the service (Daugherty et al., 1992; Hertz and Alfredsson, 2003; Ashenbaum et al., 2005), allowing 3PLs to enhance their performance and achieve competitive advantage in the long run.

These arguments collectively suggest the development of our third research hypothesis:

\section{$\mathrm{H}_{3}$ Logistics capabilities have a positive impact on 3PLs' performance.}

In fact, this assumption is consistent with the concept of the mediating factor, which is the variable that better explains the relationship between IT adoption and firm performance. This concept is clarified by Kim et al. (2008), who argue that IT adoption can create new market 
opportunities for 3PLs via the development of advanced capabilities and, in turn, of customised services. These arguments suggest the development of our fourth research hypothesis, which clarifies and extends our previous three hypotheses.

$\mathrm{H}_{4}$ Logistics capabilities mediate the relationship between IT adoption and 3PLs' performance.

\section{Research methodology}

\subsection{Measures definition}

Measures definition has been organised in two steps. First, a literature review has been conducted to identify appropriate measures of the variables included in our study, namely three main variables (information technology adoption [IT], logistics capabilities [LC] and firm performance [FP]) and four control variables (age of the company $[\mathrm{A}]$, geographical reach $[\mathrm{G}]$, customer concentration [C] and size of the company [S]). Second, two focus groups were held in order to obtain useful feedback on the measures identified. The focus groups were participated by academics and executives (IT managers of 3PLs, IT consultants and directors of an Italian logistics association). The focus groups helped us validate the measures identified in the literature by confirming that the variables used reflect, adequately, the coverage of our main variables. The focus groups were also involved in testing the suitability and comprehensibility of the questionnaire based on the measures identified. A synthesis of the main contributions of the literature used for defining the measures of the variables is described in the remainder of this section.

In the supply chain management field IT adoption [IT] has been measured in a generic way, in terms of comparison with competitors and industry standards (Wu et al., 2006, Sanders, 2007). In the logistics field, high-level variables measuring the importance given by the management to IT have been used. For instance, Lai et al. (2006) and Lai et al. (2008) proposed different dimensions of IT importance, such as IT valence, IT orientation, and IT commitment. Recent studies propose to measure the degree of IT adoption on the basis of the number of technologies adopted (Jin, 2006) or the intensity of use of different technologies ( $\mathrm{Li}$ et al. 2009). This approach, not previously used in 3PLs-related studies, allows a better assessment of the 
technological profile of companies. A review of the literature on the taxonomies of IT used in logistics systems (Piplani et al., 2004, Pokharel, 2005 and Lin and Jung, 2006) helped us to define the specific items to be included in the measurement of IT adoption (Table I.a). In accordance to Jin (2006) and the focus groups held before the questionnaire investigation, the items measuring IT adoption are binary, evaluating the adoption or the non-adoption of a specific technology by a respondent. In fact, during the focus groups, participants encountered difficulties in differentiating the degree of adoption of specific technologies.

The same approach has been used for the second variable, logistics capabilities. Adopting the 'traditionalist' approach (Larson and Halldorsson, 2004) we consider logistics capabilities [LC] as a part of the larger set of supply chain capabilities (Wu et al., 2006). Drawing on Lynch et al. (2000), Tracey et al. (2005) and the general body of literature on 3PLs, we propose to measure logistics capabilities as the service offered by 3PLs. As for IT adoption, supply chain capabilities have been measured in previous literature via high-level constructs such as supply chain integration, and collaboration. These constructs do not share a common definition and they are difficult to measure empirically. Using service offering provides clear criteria for assessing the capability profile of companies, as shown by Lai et al. (2006) and Lai et al. (2008). Moreover, the information provided by survey respondents can, for the most part, be triangulated with secondary data provided by the company itself in its website, thus confirming the validity of the approach used. A review of the literature on the taxonomies of logistics services (Van Laarhoven et al., 2000; Van Hoek, 2002; Gunasekaran and Ngai, 2003 and Lai, 2004) helped us to define the specific items to be included in the measurement of logistics capabilities (Table I.b).

As for the firm performance [FP] variable, in assessing the impact of IT on 3PLs' performance, Wang et al. (2008) focused on financial performance while e-Business Watch (2008) used sales growth and market share. In line with the approach of Jin (2006), we identified a complete set of items, measuring marketing, financial and operational performance (Table I.c). The degree of performance improvement has been measured on a four point Likert scale, from 0 (meaning no improvement) to 3 (meaning high improvement). The four point Likert scale has been used to 'force' respondents to choose a negative or positive position in relation with the item investigated (Wright and Linacre, 1989). We acknowledge that by using Likert scales we measure performance improvement on the basis of perceptual assessment of the respondents. Although using Likert scales for measuring performance improvement is a limitation of our 
work, it is worth highlighting that since the empirical analysis focuses on small and medium enterprises obtaining actual public data of company performance could have been extremely hard, if not impossible.

As for the control variables, the age of the company [A] variable measures the number of years since the foundation of the firm. The geographical reach $[\mathrm{G}]$ is an indicator of the extent of the geographical area where the provider operates. The variable takes a higher value for providers serving a wider area (0: regional area, 1: national area, 2: European area, 3: extraEuropean area). The customer concentration [C] is measured through the company's percentage of turnover generated by the five largest customers. The number of employees, measured using the EU definition of small and medium enterprises (European Commission, 2005), has been used to represent the size of the companies [S].

\section{$<$ Insert Table I $>$}

Table I. Variables and items.

\subsection{Sample and data collection}

The data for this study was obtained from a questionnaire-based survey that was submitted to 3PLs in Italy. The draft questionnaire was submitted to the focus groups, including executives and academics, in order to check the readability and possible ambiguity of the questionnaire. We decided to target small and medium sized logistics providers since they represent the vast majority of the logistics companies operating in Italy (Leonida, 2004) and in the EU (Eurostat, 2003, pp. 47-49) market. Moreover, previous empirical studies were mainly focused on large logistics service providers, whereas the academic knowledge regarding small and medium logistics providers remains limited (Gunasekaran and Ngai, 2003). The population for this study had been defined according to the data provided by the research centre of Confetra (one of the largest associations of Italian 3PL companies). This source estimates the total number of Italian 3PL companies operating in the market at 140,550 (Leonida, 2004). A draft mailing list containing 2,464 companies was randomly compiled. A number of inconsistencies were detected and the total number of companies included in the survey was reduced from 2,464 to 1,992 . The questionnaire was then mailed to 1,992 companies with a stamped addressed return envelope for respondents' returns. The total number of questionnaires returned was 169 . The questionnaires 
collected were filtered to resolve inconsistencies and anomalies. The final number of usable responses was 153 .

Furthermore, to ensure data reliability and completeness, respondents were subsequently contacted by email and telephone in order to clarify unclear responses or to add missing data. To detect any possible non-response bias, a sub-sample of non-respondents was contacted to compare their demographic characteristics (such as company age, company size and type of activity) with respondents. This analysis, performed, as in Goode and Stevens (2000), did not indicate any significant bias. These post hoc interviews have also been used to clarify the answers of some of the questions and gain further qualitative insights that will be discussed in Section 5 .

Table II provides details concerning the distribution of the sample in terms of firm size using employee bands according to the EU definition of SMEs (European Commission, 2005). Of the 153 respondents, $27 \%$ are micro companies, $43 \%$ are small companies and $30 \%$ are medium companies.

\section{$<$ Insert Table II $>$}

Table II. Respondents by firm size

\subsection{Factor analysis}

A first approach to support our research hypotheses could have been the basic investigation of the relationships among the three 'macro-variables', i.e. IT adoption, logistics capabilities and firm performance. The main drawback of this approach is that we would have lost precious information about the single items underlying the three variables of our model (Hair et al., 2005, p.104). In fact, knowing the relationships among basic items can be extremely useful from a managerial point of view: by identifying a target performance of the firm, managers can trace back which technologies are the most suitable to achieve the capabilities required to enhance the performance. Nevertheless, as suggested by Chow et al. (2007), it seems unrealistic that a single technology can lead to the development of a service; it is usually the combination of multiple technologies (basic as well as advanced) that help companies achieve superior logistics capabilities. The same rationale may be applied to the capabilities: it seems unrealistic that the achievement of a single superior capability will help companies improve their performance. 
Instead it is the development of a wider range of services as a whole that might help companies gain competitive advantage (Hertz and Alfredsson, 2003). All these considerations support our rationale of investigating the relationship at a lesser degree of aggregation than the macrovariables, i.e. among 'clusters' of information technologies, capabilities and performance. We applied an exploratory factor analysis (EFA) to the dataset in order to reduce the number of items and condense the information contained in those original items into a smaller set of new composite dimensions (i.e. the factors) with minimum loss of information. The factor analysis has been performed using the popular software SPSS.

The 15 items underlying IT adoption, the 17 items underlying logistics capabilities and the 7 items underlying firm performance (see Table I) have been independently subjected to VARIMAX-normalised rotation. The 'scree test' (Cattell, 1966) has been used in order to identify the optimal number of factors to be considered for each one of the three macro-variables. Looking at the 'elbows' in the three scree plots we decided to extract four factors for the IT adoption variable (i.e. IT_F1, IT_F2, IT_F3 and IT_F4) that explain 47.9\% of the variance, three factors for the logistics capabilities variable (i.e. LC_F1, LC_F2, LC_F3) that explain $45.7 \%$ of the variance and three factors for the firm performance variable (i.e. FP_F1, FP_F2, FP_F3) that explain $76 \%$ of the variance. The explanatory power of the factors is consistent with the results obtained by Lai (2004) in a similar study.

Table III lists the factor loadings for the rotated four-factor solution (IT adoption) and threefactor solution (logistics capabilities and firm performance). We decided to associate an item to a factor when its loading is greater than 0.5 , which is consistent with the studies in the logistics and supply chain management field (Lai, 2004; Jiang et al., 2009) and is considered satisfactory in the social sciences (Hair et al., 2005). The reliability of the factors obtained has been measured through Cronbach's alpha values. These coefficients (depicted in Table III) exceed the benchmark of 0.70 for exploratory analysis (Nunnally and Bernstein, 1994).

Factor 1 (IT_F1), the 'data gathering technologies factor', consists of EDI, barcode, radio frequency and RFID. EDI might be included in this factor because, like the other identification technologies, it can be used to retrieve data, in this case related to clients' orders. Factor 2 (IT_F2), which we will refer to as the 'basic communication technologies factor', is a combination of telephone/fax, internet access and corporate email. Factor 3 (IT_F3), the 'customer-centric technologies factor', contains mobile phones and CRM. Factor 4 (IT_F4), the 
'enterprise information technologies factor', includes LAN, WLAN and ERP. The IT adoption factors are consistent with the framework proposed by Chopra and Meindl (2003) and Li et al. (2009).

Factor 5 (LC_F1), the 'transactional capabilities factor', consists of packaging, labelling, order management, reconditioning, return management and inventory management. Factor 6 (LC_F2), the 'warehouse management capabilities factor', is a combination of optional assembly, consolidation warehousing and distribution management. Factor 7 (LC_F3), the 'postponement related capabilities factor', contains final assembly, product test/repair and product installation. The logistics capabilities factors are consistent with the framework proposed by Rabinovich et al. (1998).

Factor 8 (FP_F1), the 'effectiveness performance factor', includes operations improvement, customer service improvement and flexibility improvement. Factor 9 (FP_F2), the 'financial performance factor', is a combination of turnover improvement, expansion of market and number of customers increase. Factor 10 (FP_F3), the 'efficiency performance factor', consists of asset utilisation improvement. The firm performance factors are consistent with the framework proposed by Jin (2006).

\section{Measurement model and results}

\subsection{Factor-analytic OLS}

Our macro-variables have been measured for each questionnaire respondent according to the scores of the original 39 items (15 for IT adoption, 17 for logistics capabilities and seven for firm performance). In the measurement model, instead of using the original 39 scores for each respondent, we calculated factor scores for each of the ten factors through the concept of summated scales. According to Hair et al. (2005, p. 135), for each factor we simply compute the average score of the items representing that factor - which is used as a composite measure for the factor itself. The use of the unweighted average of the items as a composite factor can be easily justified for our ten factors, due to the homogeneity of the items underlying them (a property directly derived from the way they have been constructed). The ordinary least square (OLS) method has been used to estimate the coefficients of the regression model. As suggested by Greene (2008, p.150), this technique can be used to test the relationships between variables 
when the latter can be considered continuous. In our case, the applicability of the model is verified since we are testing the relationships between variables that are the average of items and, thus, can be considered continuous. The OLS technique has been complemented with a regression residuals analysis. For each hypothesis and for each dependent variable (factor) it is possible to write a regression equation that is a function of all the independent variables (factors) and all the control variables. The complete list of regression equations used in the OLS model is shown in Table IV. The OLS regression has been performed using the specific econometric software GRETL.

\subsection{Results of the OLS regression analysis and hypothesis testing}

Our hypotheses are concerned with the mediating effect of logistics capabilities between IT adoption and firm performance. In order to identify the mediating effect of logistics capabilities the Baron and Kenny approach has been adapted to this study (Baron and Kenny, 1986). Adopting the same terminology we will call the IT adoption factors 'initial variables', the firm performance indicators 'outcomes' and the logistics capabilities 'mediators'. The results described in the remainder of this section will be then discussed in Section 5.

First, it is necessary to show that the initial variable is correlated with the outcome. This, in turn, is equivalent to test hypothesis 1 . The results of the OLS regression analysis (Table IV.a.) show that all the statistically significant coefficients are positive and quite large, thus supporting our assumption for some of the factors. In particular, data gathering technologies (IT_F1) are strongly related to effectiveness performance (PF_F1) and efficiency performance (PF_F3). The correlation analysis shows a coefficient of 4.45 (significant at the 0.01 level) and a coefficient of 4.97 (significant at the 0.05 level) respectively. Moreover, it is possible to highlight a strong correlation between enterprise information technologies (IT_F4) and financial performance, FP_F2 (the coefficient of 3.46 is significant at the 0.05 level). There is also a correlation between the size of the firm (S) and the efficiency performance (PF_F3): the coefficient of 6.02 is significant at the 0.05 level. Finally, the presence of CRM and mobile phones in a firm (IT_F3) seems to be correlated to the efficiency performance (FP_F2), whereas basic communication technologies (IT_F2) seem to be not significant for our model. This means that hypothesis 1 has been adequately supported by the data. In fact, the adoption of data gathering technologies has a 
positive impact on the effectiveness and efficiency of operations of 3PLs, whereas the adoption of enterprise information technologies has a positive impact on their financial performance.

As a second step, Baron and Kenny suggest to test the correlation between the initial variable and the mediator. Based on the OLS regression analysis (Table IV.b), IT_F1 (data gathering technologies factor) is strongly correlated with LC_F1 (transactional capabilities factor) since the coefficient of 2.94 is significant at the 0.01 level. This supports hypothesis 2 . It is, therefore, possible to affirm that the adoption of data gathering technologies has a positive impact on the transactional capabilities of 3PLs. Other relationships between IT adoption variables and logistics capabilities, although statistically significant, reported correlation coefficients near zero.

As a third step, Baron and Kenny suggest to test the correlation between the mediator and the outcome. Whereas the original approach (Baron and Kenny, 1986) suggests that the initial variable should be also included in the regression equations used to support this step, James and Brett (1984) argue that the inclusion of the initial variable in the test is unnecessary. Thus, this step is supported by the regression analysis performed to investigate hypothesis 3 . The regression (Table IV.c) shows that LC_F1 (transactional capabilities factor) is strongly related to the effectiveness performance factor FP_F1 (coefficient of 5.06 significant at the 0.01 level) and the efficiency performance factor FP_F3 (coefficient of 2.57 significant at the 0.01 level). Hypothesis 3 is, thus, supported and we can affirm that transactional capabilities have a positive impact on 3PLs' performance in terms of improvement of effectiveness and efficiency of operations. The high value of the constant coefficient in the testing of hypothesis 3 , even though statistically significant, is not relevant to our purposes since we use the OLS technique only to test relationships among variables (if OLS were used as a forecasting technique, the constant coefficients would be relevant since they would represent the 'level' of the demand).

The fourth step of the Baron and Kenny approach is concerned with establishing whether the mediator completely mediates the relationship. In the case of complete mediation, Baron and Kenny argue that the effect of the initial variable on the outcome controlling for the mediator should be zero. We performed the regressions exclusively for those variables that seem to be strongly correlated. Thus IT_F1 (data gathering technologies factor) is the 'initial variable', FP_F1 (effectiveness performance factor) and FP_F3 (efficiency performance factor) are the 'outcomes' and LC_F1 (data gathering technologies factor) is the 'mediator' (Table IV.d). In this case, the significance of relevant regression coefficients is generally lower than in previous 
regressions. Nevertheless, it is useful to point out that all the steps of the Baron and Kenny method are stated in terms of zero and nonzero coefficients and therefore the significance of the coefficients is not extremely relevant to this approach. First, it is possible to identify a correlation effect between the outcomes and the mediator. Moreover, the correlation coefficients obtained when assessing the relationship between the initial variable and the mediator are significantly lower than the values obtained in previous regression analysis (Table IV.b). This seems to support a mediation effect. Nevertheless, since these regression coefficients are all nonzero, the complete mediation effect is not supported by the data. In fact, complete mediation is extremely rare to obtain in the social sciences (Frazier et al., 2004), due to the fact that this test is not performed in a closed environment and the sample of respondents is influenced by a number of exogenous factors that a questionnaire could only partially take into account. As far as hypothesis 4 is concerned, it is possible to affirm that transactional capabilities partially mediate the relationship between data gathering technologies and 3PLs' performance in terms of improvement of effectiveness and efficiency of operations.

\section{Discussion of results}

Due to the globalisation of supply chain architectures, information management is assuming a key importance as an integrative element of SCM strategy. As a result, the use of IT should be effectively used among all supply chain partners in order to avoid that poor IT resource management by one or more actors in the supply chain could have negative repercussions on the performance of the entire supply chain in terms of planning ability, costs and customer service (Ovalle and Marquez, 2003). This appears particularly true in the case of 3PLs where the rapid diffusion of IT has had significant impact on changing their traditional core-competences and supply chain role. In order to address this new role beyond the dyad, 3PLs are currently required to manage information flows along the entire supply chain. This has forced 3PLs to accelerate investment in IT applications. For this reason the assessment of the IT impact on company performance has become a critical issue. As this topic has been little investigated in the current literature, the main objective of this paper is to fill this gap.

Drawing on the resource based view theory, our framework identifies IT adoption as the resource that allows 3PLs to develop specific logistics capabilities, which allow 3PLs to enhance 
their performance and thus achieve competitive advantage. In order to explore this relationship the following research hypotheses have been tested:

$H_{l}$ IT adoption has a positive impact on 3PLs' performance

$\mathrm{H}_{2}$ IT adoption has a positive impact on 3PLs' logistics capabilities

$\mathrm{H}_{3}$ Logistics capabilities have a positive impact on 3PLs' performance

$\mathrm{H}_{4}$ Logistics capabilities mediate the relationship between IT adoption and 3PLs' performance

The results of data analysis show a positive correlation between the adoption of data gathering and enterprise information technologies and 3PLs' performance. This reinforces the idea that information technology investment is a critical area to achieve competitive advantage in the logistics sector. Moreover, the adoption of data gathering technologies allow 3PLs to develop transactional capabilities that are core in enhancing the value added services offered to their clients. In turn, higher levels of logistics transactional capabilities imply higher levels of performance in terms of efficiency and effectiveness, thus confirming our theory that advanced logistics capabilities are the competences that lead 3PLs towards competitive advantage. It has been possible to show that transactional logistics capabilities are the mediating factors between data gathering technologies and 3PLs' efficiency and effectiveness performance. This last result allows us to validate our resource based view overall framework. A more detailed discussion and comparison with the existing literature of the above hypotheses has been given in following two sections. In particular, Paragraph 5.1 discusses hypothesis $\mathrm{H}_{1}$ while Paragraph 5.2 is focused on the discussion of hypotheses $\mathrm{H}_{2}, \mathrm{H}_{3}$ and $\mathrm{H}_{4}$.

\subsection{IT adoption and firm performance}

First, we identified a positive correlation between data gathering technologies (EDI, barcode, radio frequency and RFID) and performance related to efficiency (asset utilisation improvement) and effectiveness (operations improvement, customer service improvement and flexibility improvement). According to the post hoc qualitative interviews performed, 3PLs implementing barcode, radio frequency and RFID experienced increased productivity in the processes of receiving and dispatching of goods. Moreover, EDI greatly contributed in reducing the daily time required to contact clients and to input data into the information systems. Effectiveness performance could be linked to better quality and consistency of the data obtained via the implementation of data gathering technologies. Some research in the logistics and supply chain 
management field points out a general improvement of efficiency and effectiveness performance due to the adoption of identification technologies (Calder and Marr, 1998; Kärkäinnnen and Hölmstrom, 2002), information sharing technologies (Lewis and Talalayevsky, 2000; James et al. 2004; Devaraj et al., 2007) or both types of technologies (Chow et al. 2007). Our results are consistent with their assumptions. The direct and positive correlation between specific IT technologies and firm performance obtained in this study is an extremely important result, since previous studies, using specific technologies as variables, reveal mixed results in this regard (see Jin, 2006; Li et al., 2009; Olorunniwo and Li, 2010). One exception is a recent paper by Lin and Ho (2009), where the authors find a positive correlation between the willingness to adopt RFID technologies and supply chain performance. Previous survey-based studies focused on 3PLs' capabilities and performance (Lai et al., 2006; Lai et al., 2008) do not allow a direct comparison with this research since their IT variables have been measured in a much more generic way (e.g. IT valence, IT orientation, IT commitment).

Second, we found a positive correlation between enterprise information technologies (LAN, WLAN, ERP) and financial performance (turnover improvement, expansion of market and number of customers increase). These technologies enabled 3PLs to collect data from many divisions of firms in one central repository. 3PLs interviewed experienced a better control of companies' process that enabled them to make informed decisions on the basis of financial and marketing indicators. These results are consistent with the ones obtained by Lai et al. (2006) and Lai et al. (2008). Moreover, logistics providers might perceive enterprise information systems strictly linked to financial performance since these solutions are more closely related to the management of transactional, accounting and financial processes of the firms (Chopra and Meindl, 2003).

Third, the adoption of CRM and mobile phones is correlated to efficiency performance (asset utilisation improvement). This evidence may be explained considering 3PLs' core business. In fact, the advanced features of mobile phones help 3PLs in coordinating transport operations. Giaglis et al. (2004) suggested a similar explanation with specific reference to dynamic routing software. As CRM helps companies in improving knowledge about customer requirements (Gopal and Cline, 2007) this correlation indicates that the adoption of this IT tool may be better exploited by those 3PLs focussed on services beyond transportation (e.g. warehousing and distribution). 
Fourth, the positive relationship between company size and the efficiency performance can be ascribed to the economies of scale and scope that can be achieved by larger providers especially with reference to transportation and warehousing (Sum and Teo, 1999; Hertz and Alfredsson, 2003; Panayides, 2004).

Finally, basic technologies (telephone/fax, internet access and corporate email) do not show significant correlation to firm performance. These technologies are mature and adopted by the great majority of the firms in our sample. Thus, they cannot be considered as distinctive elements that contribute towards the differentiation of 3PLs' resource portfolios. Norek and Langley (2007) suggest that logistics providers' clients consider similar technologies as a minimum requirement to subcontract or outsource logistics services to third parties.

\subsection{Logistics transactional capabilities as a mediating factor}

First, we found a positive correlation between data gathering technologies (EDI, barcode, radio frequency and RFID) and transactional capabilities (packaging, labelling, order management, reconditioning, return management and inventory management). According to the post hoc qualitative interviews performed, 3PLs experienced an immediate beneficial impact from data gathering technologies (and identification technologies in particular) on simple processes such as packaging and labelling. The introduction of data gathering technologies also helped 3PLs in acquiring a better visibility on supply chain processes. Supply chain visibility has enhanced logistics providers' ability to make timely, informed decisions increasing their capability of better managing and controlling complex processes such as order management, reconditioning, return management and inventory management. These results are consistent with extant literature. Van Hoek (2001) suggests that the use of technologies such as EDI-based advance shipping notices can improve the integration capabilities of the supply chain. Delfmann et al. (2002) for instance, theorise that IT adoption (and e-Commerce in particular) can help logistics providers to acquire the capabilities to customise their services. Norek and Langley (2007) identify tracking technologies and RFID as potential drivers for the development of new valueadded services for logistics providers. Li et al. (2009) obtained similar results to the ones presented in this paper. In fact, they identified a strong correlation between the adoption of some information technologies (including, also, identification solutions and EDI) and the integration capabilities of the adopting firm. 
Second, we found a positive correlation between transactional capabilities (packaging, labelling, order management, reconditioning, return management and inventory management) and performance measures related to efficiency (asset utilisation improvement) and effectiveness (operations improvement, customer service improvement and flexibility improvement). 3PLs interviewed affirmed that better control and visibility on transactional processes helped them to improve the overall performance of the firm. In fact, since transactional capabilities represent core competences for many logistics providers interviewed, even small improvements in these capabilities led to direct positive repercussions on the company performance. Similar results have been obtained by Lai (2004), who linked the achievement of logistics transactional capabilities such as order processing, assembling and labelling to the achievement of superior performance in terms of efficiency and effectiveness. According to the post hoc qualitative interviews performed, 3PLs confirmed that the capabilities acquired via the adoption of new technologies could often be directly offered as services to their existing customers, although 3PLs' clients were not always willing to pay additional fees for the new services. Nevertheless, the acquired capabilities have allowed 3PLs to be more efficient and perform logistics tasks at lower costs. Moreover, the increase in the effectiveness of their operations and in their customer service helped some 3PLs to secure contracts with clients for future years. These results are consistent with several studies, suggesting a strong relationship between the development of services and 3PLs performance (Daugherty et al., 1992; Hertz and Alfredsson, 2003; Ashenbaum et al., 2005). The service dimension has also been considered in recent studies linking IT adoption to 3PLs performance (Lai et al., 2006; Lai et al, 2008).

Finally, our results showed that transactional logistics capabilities partially mediate the relationship between IT adoption and firm performance. This important result is consistent with Kim et al. (2008), suggesting that the implementation of identification technologies can support 3PLs in offering advanced packaging and labelling services (e.g. RFID labelling) and thus sustain competitive advantage. Olorunniwo and Li (2010) suggest a similar result by showing that the IT adoption combined with an enhancement of operational capabilities affects reverse logistics performance positively. 


\section{Conclusions and implications}

\subsection{Research and managerial implications}

From the research standpoint, this study provides a resource based view (RBV) perspective to understand the relationship between IT adoption, logistics capabilities and firm performance. The resource based view seems to be a key framework for academic research on 3PLs (Lai, 2004; Lai et al., 2008). Whereas previous studies have not shown a clear path when testing the relationship between IT adoption and firm performance, we found positive correlations between data gathering technologies and efficiency and effectiveness performance along with positive correlations between enterprise information technologies and financial performance. In addition, we identified the adoption of data gathering technologies for improving transactional capabilities as the resource that can help 3PLs to achieve superior performance in terms of efficiency and effectiveness. A final research contribution of this paper is given by the refinement of the measures for the variables considered. IT adoption has been measured looking at the specific technologies adopted and logistics capabilities via a detailed list of services.

Some implications for 3PLs' managers can be drawn from the survey results. Previous empirical studies, focussing on large logistics service providers generally, highlight that the logistics sector is characterised by higher technological innovation than other industries (Norek and Langley, 2007). As an exemplary case, Van Hoek and Chong (2001) described how UPS mastered technological innovation to create a virtual supply chain for the benefit of their clients. Nevertheless, as recently suggested by the President and CEO of FedEX Supply Chain (O'Reilly, 2010), large 3PLs can afford the daunting costs of high IT adoption mainly because they are able to put the technological systems to work for multiple clients. In fact, high transaction volumes, solely, justify the adoption of technologies for achieving automation and innovation in supply chain processes (Archer et al., 2008). A positive correlation between the size of the companies and IT adoption has also been found in the present study and has also been highlighted by other contributions in the supply chain management field (Pearcy and Giunipero, 2003). This also contributes to explain the different usage of IT between large and small logistics companies. Large logistics companies achieve significant benefits from technology investment in terms of managing global supply chain and warehouse networks. In the case of small logistics providers, information technology innovation is used as leverage to emancipate themselves from 
the status of simple subcontractors (Paché, 1996). According to the post hoc qualitative interviews performed, the small and medium enterprises included in our sample benefit from economy of scale by a lesser extent than larger enterprises. In addition, small and medium logistics providers may have difficulties in accessing the financial resources necessary to adopt and maintain advanced technological solutions, especially during recession. Therefore, it is extremely important for small and medium 3PLs to correctly prioritise their technological investments. Unfortunately, many such companies lack strategic plans for implementing information technologies (Gunasekaran and Ngai, 2003). For this reason, the results of this research may be used by logistics managers embarking on IT investment projects to help them devise a systematic and planned approach to technology implementation. Managers looking for efficiency and effectiveness improvements should consider a set of data gathering technologies (EDI, barcode, radio frequency and RFID) that could help them to improve their logistics transactional capabilities and, in turn, their performance. Managers looking for marketing and finance performance enhancements should consider the implementation of a set of enterprise information technologies (LAN, WLAN, ERP).

The results could be used by IT vendors to better understand the current level of technology implementation by 3PLs. IT vendors, who are knowledgeable about logistics technologies, should proactively help 3PLs in achieving this challenging task. Moreover, the study allows the identification of specific technologies that have the higher potential to improve a company's performance and, therefore, could be more attractive for 3PL companies. This may result in designing and marketing IT applications that are more closely aligned with the business characteristics of logistics companies.

Finally, from a policy perspective, the findings emerging from the empirical investigations can help decision-makers devising targeted policy to accelerate the rate of IT diffusion in 3PL companies in order to sustain and develop the sector.

\subsection{Limitations and directions for future research}

The study is exploratory in nature and, as such, has been subject to some limitations that do not reduce the significance of the findings but, instead, suggest directions for future research. 
First, the survey focuses on the Italian logistics service market. Although the structure of this sector is highly fragmented as in other countries, one must exercise caution in extrapolating the results geographically. Therefore, comparative studies between small logistics service companies operating in different countries may be beneficial.

Second, the present study effectively combines survey methodology with post hoc qualitative interviews. Nevertheless, the amount of qualitative insights obtained via the interviews is limited. Further research may focus on case-study-based analysis in order to achieve a deeper understanding of drivers and barriers affecting IT adoption and their impact on 3PLs' performance. Moreover case study investigation could help refine the variables and constructs used in the present research.

Third, although this research offers precise guidelines that could be used by logistics providers for defining their IT strategy, it does not provide a systematic and planned approach to implementation based on the expected impact of benefits and costs ensuing from the adoption of different technologies. On the basis of the results provided by this paper, further quantitative studies, using a similar approach as the one, used by Sharma (2008 and 2010), could suggest a decision-making framework to support the technology adoption in 3PLs.

Finally, the main motivation of this research resides in the growing need for measuring the performance of logistics providers. In fact, the evolution of 3PLs' role beyond dyadic relationships entrusts these actors with the important task of integrating and accelerating physical and information flows at multiple levels of the supply chain. Although this research takes into account the interactions between 3PLs, clients and other logistics providers, further studies could investigate the hard and soft skills required by 3PLs to manage this complex set of relationships and the role of IT in supporting the development of these skills.

\section{Acknowledgments}

The authors would like to thank Professor Chee Wong, the editor and the anonymous reviewers for their helpful comments and suggestions. 
Table I. Variables and items

Table I.a. IT adoption variable

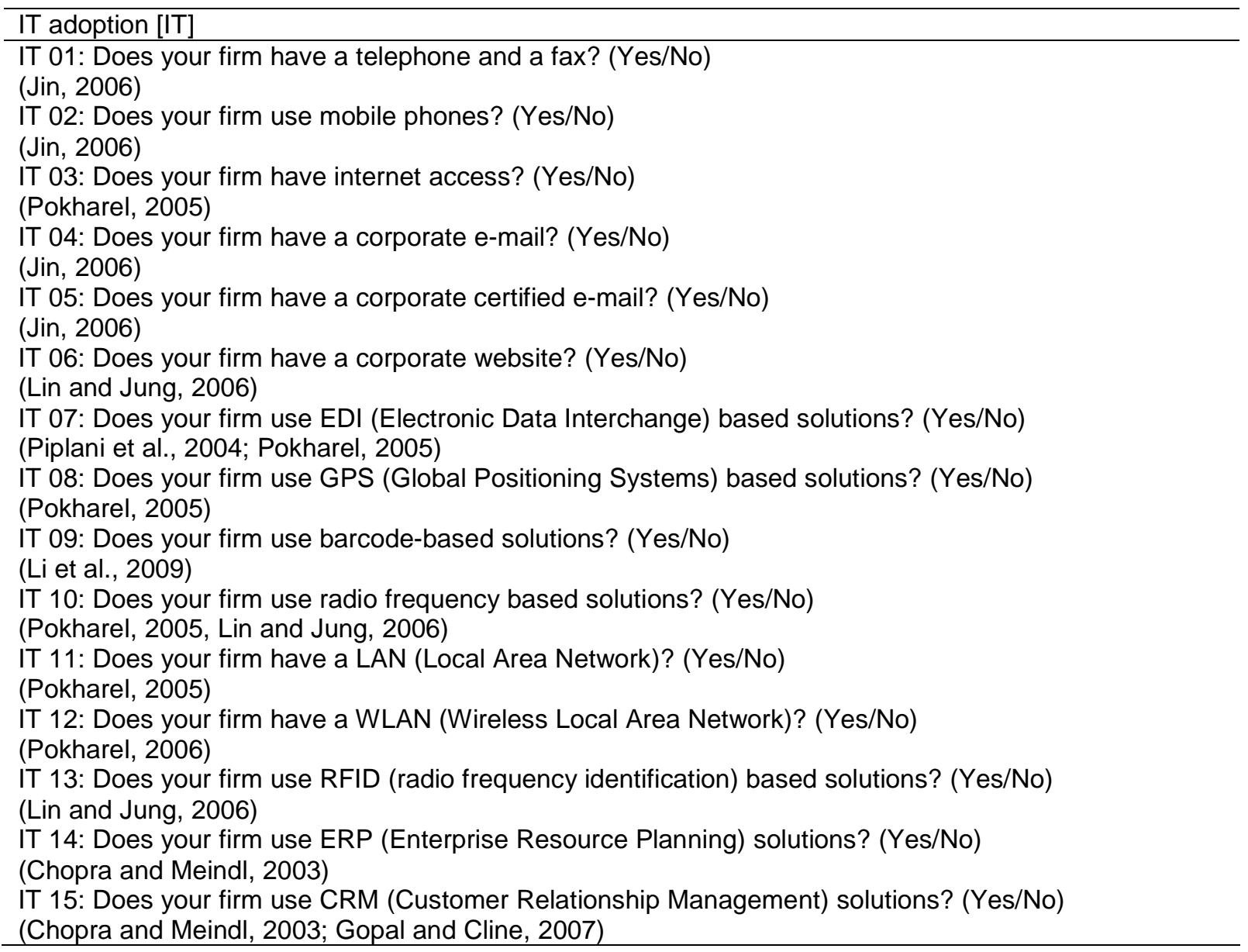


Table I.b. Logistics capabilities variable

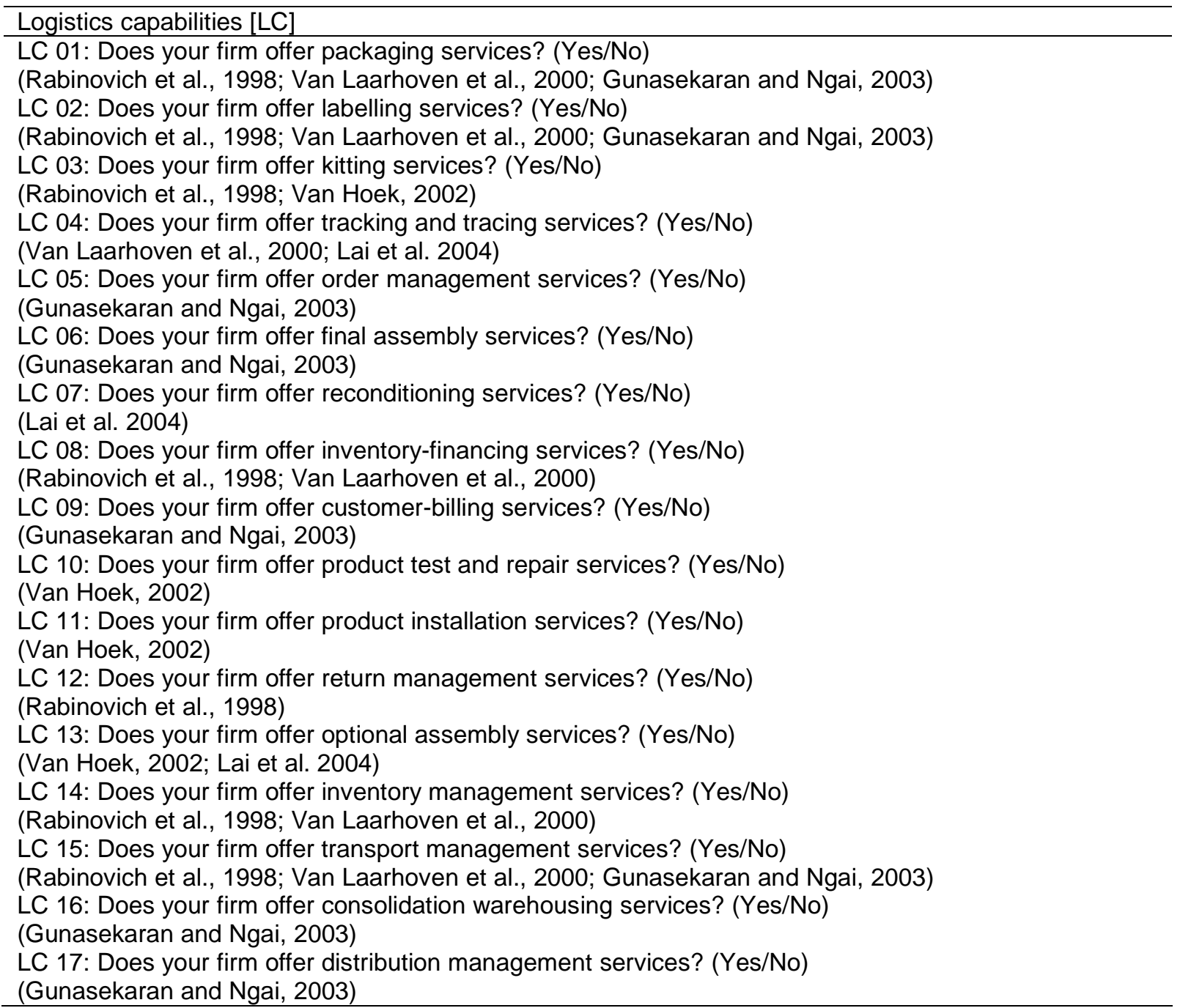


Table I.c. Firm performance variable

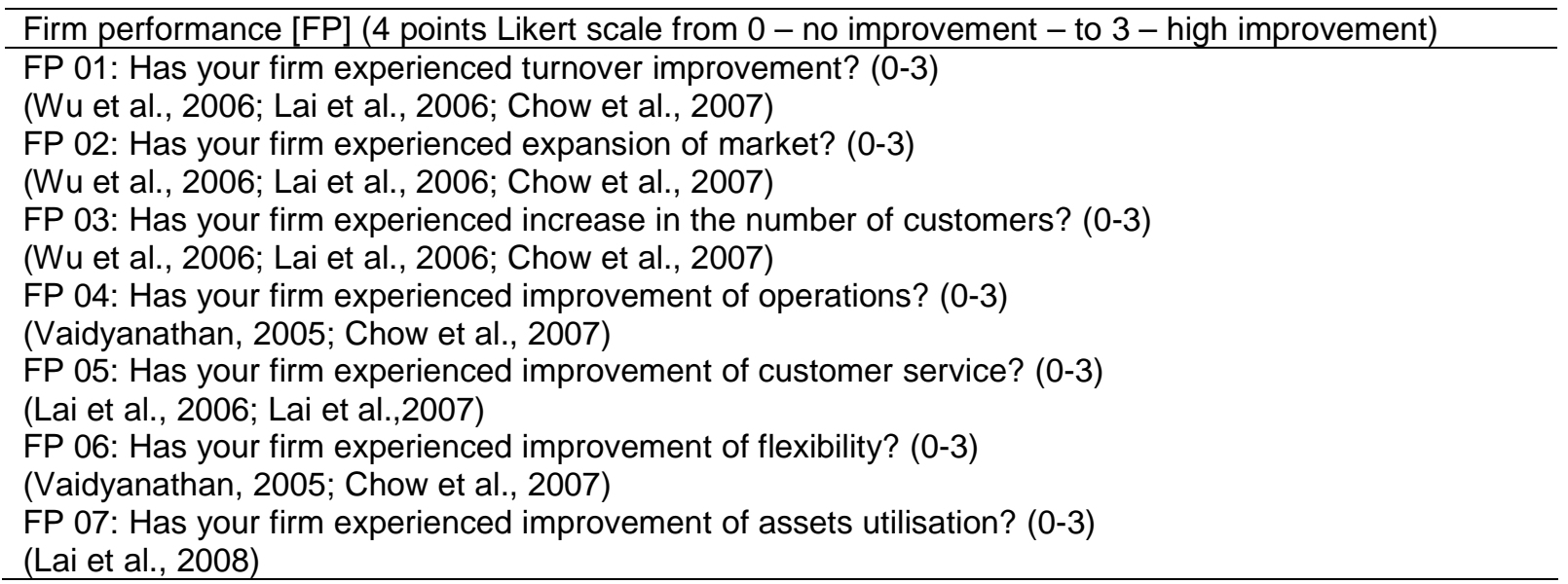

Table I.d. Control variables

Control variables

A: For how many years your firm has been active in the logistics industry?

G: Does your firm operate in a regional area (0), in a national area (1) in a European area (2) or in a extra-European area (3)?

C: Which percentage of your turnover do your fist five customers generate?

S: What is the size of your firm? ( 0 : employees < 10; 1: 11-20 employees; 2: 21-50 employees; 3: 51-95 employees; 4: employees > 95).

Table II. Respondents by firm size

\begin{tabular}{lcc}
\hline Employee bands & $\mathrm{N}$ & $\%$ \\
\hline Micro (less than 10) & 41 & 26.8 \\
Small (from 10 to 50) & 65 & 42.5 \\
Medium (from 51 to 250) & 47 & 30.7 \\
\hline Total & 153 & 100 \\
\hline
\end{tabular}


Table III. Rotated factors results (correlations higher than 0.5 are highlighted)

Table III.a. IT adoption variable

\begin{tabular}{|c|c|c|c|c|c|}
\hline & Items & $\begin{array}{c}\text { Factor } 1 \\
\text { [IT_F1] } \\
\text { Cronbach's } \\
\alpha=0.86\end{array}$ & $\begin{array}{c}\text { Factor } 2 \\
\text { [IT_F2] } \\
\text { Cronbach's } \\
\alpha=0.83\end{array}$ & $\begin{array}{c}\text { Factor } 3 \\
\text { [IT_F3] } \\
\text { Cronbach's } \\
\alpha=0.99\end{array}$ & $\begin{array}{c}\text { Factor } 4 \\
\text { [IT_F4] } \\
\text { Cronbach's } \\
\alpha=0.78\end{array}$ \\
\hline \multirow{15}{*}{$\begin{array}{l}\text { 틀 } \\
\text { 음 } \\
\text { 응 } \\
\text { 음 } \\
上\end{array}$} & IT 01: Telephone and fax & -0.117 & 0.555 & 0.388 & 0.163 \\
\hline & IT 02: Mobile phones & -0.050 & 0.296 & 0.636 & 0.140 \\
\hline & IT 03: Internet access & 0.049 & 0.720 & -0.038 & 0.081 \\
\hline & IT 04: Corporate email & 0.027 & 0.780 & 0.012 & 0.085 \\
\hline & IT 05: Certified email & 0.249 & 0.112 & 0.490 & -0.540 \\
\hline & IT 06: Corporate website & 0.399 & 0.451 & -0.382 & -0.027 \\
\hline & IT 07: EDI & 0.595 & 0.151 & 0.111 & 0.134 \\
\hline & IT 08: GPS & 0.041 & 0.320 & 0.124 & -0.106 \\
\hline & IT 09: Barcode & 0.763 & 0.031 & -0.058 & 0.234 \\
\hline & IT 10: Radio frequency & 0.709 & 0.107 & -0.060 & 0.194 \\
\hline & IT 11: LAN & 0.143 & 0.176 & 0.024 & 0.667 \\
\hline & IT 12: WLAN & 0.265 & 0.027 & 0.092 & 0.610 \\
\hline & IT 13: RFID & 0.522 & -0.124 & 0.172 & -0.020 \\
\hline & IT 14: ERP & 0.291 & -0.109 & 0.318 & 0.548 \\
\hline & IT 15: CRM & 0.385 & -0.046 & 0.506 & 0.077 \\
\hline
\end{tabular}


Table III.b. Logistics capabilities variable

\begin{tabular}{|c|c|c|c|c|}
\hline & Items & $\begin{array}{c}\text { Factor } 1 \\
\text { [LC_F1] } \\
\text { Cronbach's } \\
\alpha=0.90 \\
\end{array}$ & $\begin{array}{c}\text { Factor } 2 \\
\text { [LC_F2] } \\
\text { Cronbach's } \\
\alpha=0.87 \\
\end{array}$ & $\begin{array}{c}\text { Factor } 3 \\
\text { [LC_F3] } \\
\text { Cronbach's } \\
\alpha=0.87\end{array}$ \\
\hline \multirow{17}{*}{ 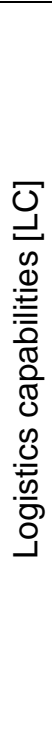 } & LC 01: Packaging & 0.644 & 0.042 & 0.283 \\
\hline & LC 02: Labelling & 0.742 & 0.161 & 0.210 \\
\hline & LC 03: Kitting & 0.353 & 0.408 & 0.351 \\
\hline & LC 04: Tracking/tracing & 0.473 & 0.423 & -0.070 \\
\hline & LC 05: Order management & 0.505 & 0.198 & 0.281 \\
\hline & LC 06: Final assembly & 0.292 & -0.145 & 0.732 \\
\hline & LC 07: Reconditioning & 0.659 & -0.017 & 0.120 \\
\hline & LC 08: Inventory financing & 0.361 & -0.119 & -0.197 \\
\hline & LC 09: Customer-billing & 0.084 & 0.212 & 0.229 \\
\hline & LC 10: Product test/repair & 0.189 & 0.001 & 0.731 \\
\hline & LC 11: Product installation & -0.023 & 0.083 & 0.651 \\
\hline & LC 12: Return management & 0.587 & 0.226 & 0.275 \\
\hline & LC 13: Optional assembly & 0.121 & 0.518 & 0.462 \\
\hline & LC 14: Inventory management & 0.693 & 0.049 & 0.095 \\
\hline & LC 15: Transport management & -0.409 & 0.484 & 0.050 \\
\hline & LC 16: Consolidation warehousing & 0.114 & 0.776 & -0.114 \\
\hline & LC 17: Distribution management & 0.041 & 0.760 & 0.072 \\
\hline
\end{tabular}

Table III.c. Firm performance variable

\begin{tabular}{|c|c|c|c|c|}
\hline & Items & $\begin{array}{c}\text { Factor } 1 \\
\text { [FP_F1] } \\
\text { Cronbach's } \\
\alpha=0.79 \\
\end{array}$ & $\begin{array}{c}\text { Factor } 2 \\
\text { [FP_F2] } \\
\text { Cronbach's } \\
\alpha=0.77 \\
\end{array}$ & $\begin{array}{c}\text { Factor } 3 \\
\text { [FP_F3] } \\
\text { Cronbach's }\end{array}$ \\
\hline \multirow{7}{*}{ 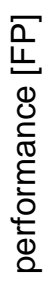 } & FP 01: Turnover improvement & 0.297 & 0.831 & 0.007 \\
\hline & FP 02: Expansion of market & -0.186 & 0.787 & 0.161 \\
\hline & FP 03: Number of customers increase & 0.196 & 0.846 & 0.097 \\
\hline & FP 04: Operations improvement & 0.896 & 0.018 & -0.013 \\
\hline & FP 05: Customer service improvement & 0.747 & 0.083 & 0.419 \\
\hline & FP 06: Flexibility improvement & 0.749 & 0.192 & 0.250 \\
\hline & FP 07: Asset utilisation improvement & 0.250 & 0.149 & 0.921 \\
\hline
\end{tabular}


Table IV. Results of OLS regression analysis

Table IV.a. Firm performance and IT adoption (H1)

\begin{tabular}{cccccccccc}
\hline H1 & Constant & IT_F1 & IT_F2 & IT_F3 & IT_F4 & A & G & C & S \\
\hline FP_F1 & 0.68 & $\mathbf{4 . 4 5}^{\star \star *}$ & 0.80 & 0.00 & 0.13 & 0.48 & 0.53 & 0.60 & 0.07 \\
FP_F2 & 0.60 & 0.08 & 0.01 & 0.64 & $\mathbf{3 . 4 6}^{\star *}$ & 0.63 & 0.49 & 0.02 & 0.17 \\
FP_F3 & 0.02 & $\mathbf{4 . 9 7}^{\star \star}$ & 0.39 & $\mathbf{2 . 5 2}^{\star}$ & 0.83 & 1.28 & 0.53 & 0.64 & $\mathbf{6 . 0 2}^{\star *}$ \\
\hline
\end{tabular}

${ }^{*}$ Significance $<0.1 ;{ }^{* *}$ Significance $<0.05 ;{ }^{* * *}$ Significance $<0.01$

Regression equations:

$F P \_F 1=\beta_{0}+\beta_{1} I T \_F 1+\beta_{2} I T \_F 2+\beta_{3} I T \_F 3+\beta_{4} I T \_F 4+\beta_{5} A+\beta_{6} G+\beta_{7} C+\beta_{8} S$

FP F2 $=\beta_{0}+\beta_{1} I T F 1+\beta_{2} I T F 2+\beta_{3} I T F 3+\beta_{4} I T F 4+\beta_{5} A+\beta_{6} G+\beta_{7} C+\beta_{8} S$

$F P\left[F 3=\beta_{0}+\beta_{1} I T-F 1+\beta_{2} I T-F 2+\beta_{3} I T+F 3+\beta_{4} I T-F 4+\beta_{5} A+\beta_{6} G+\beta_{7} C+\beta_{8} S\right.$

Table IV.b. Logistics capabilities and IT adoption (H2)

\begin{tabular}{cccccccccc}
\hline H2 & Constant & IT_F1 & IT_F2 & IT_F3 & IT_F4 & A & G & C & S \\
\hline LC_F1 & 0.06 & $\mathbf{2 . 9 4}^{\star \star *}$ & 0.00 & 0.01 & 0.00 & 0.02 & 0.01 & 0.07 & 0.03 \\
LC_F2 & 0.00 & $\mathbf{0 . 2 6}^{\star \star *}$ & 0.00 & 0.02 & 0.04 & 0.00 & 0.01 & 0.00 & 0.00 \\
LC_F3 & 0.00 & $\mathbf{0 . 1 4}^{\star \star}$ & 0.00 & $\mathbf{0 . 2 9}^{\star \star *}$ & 0.02 & 0.01 & 0.03 & $\mathbf{0 . 0 7}^{*}$ & 0.00 \\
\hline
\end{tabular}

${ }^{\star}$ Significance $<0.1{ }^{* \star}$ Significance $<0.05$; ${ }^{* \star}$ Significance $<0.01$

Regression equations:

$L C \_F 1=\beta_{0}+\beta_{1} I T \_F 1+\beta_{2} I T \_F 2+\beta_{3} I T+F 3+\beta_{4} I T+F 4+\beta_{5} A+\beta_{6} G+\beta_{7} C+\beta_{8} S$

$L C F 2=\beta_{0}+\beta_{1} I T F 1+\beta_{2} I T F 2+\beta_{3} I T F 3+\beta_{4} I T F 4+\beta_{5} A+\beta_{6} G+\beta_{7} C+\beta_{8} S$

$L C \_F 3=\beta_{0}+\beta_{1} I T \_F 1+\beta_{2} I T \_F 2+\beta_{3} I T \_F 3+\beta_{4} I T \_F 4+\beta_{5} A+\beta_{6} G+\beta_{7} C+\beta_{8} S$

Table IV.c. Firm performance and logistics capabilities (H3)

\begin{tabular}{ccccccccc}
\hline H3 & Constant & LC_F1 & LC_F2 & LC_F3 & A & G & C & S \\
\hline FP_F1 & $\mathbf{8 1 . 6 3}^{\star \star *}$ & $\mathbf{5 . 0 6}^{\star \star *}$ & 0.07 & 0.21 & 0.45 & 0.56 & 0.84 & 0.03 \\
FP_F2 & $\mathbf{2 1 . 9 5}^{\star \star *}$ & 0.09 & 0.42 & 0.73 & 0.34 & 0.73 & 0.00 & 0.10 \\
FP_F3 & $\mathbf{2 7 . 7 0}^{\star * *}$ & $\mathbf{2 . 5 7}^{\star \star}$ & 0.25 & 0.07 & 1.10 & 0.20 & 0.82 & 10.08 \\
\hline
\end{tabular}

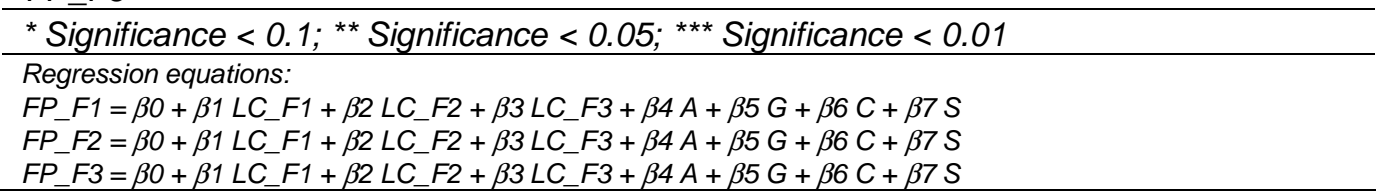


Table IV.d. Logistics capabilities mediate IT adoption and firm performance (H4)

\begin{tabular}{cccccccc}
\hline H4 & Constant & IT_F1 & LC_F1 & A & G & C & S \\
\hline FP_F1 & $\mathbf{1 . 8 5}^{\star \star *}$ & $\mathbf{0 . 5 4}^{\star}$ & $\mathbf{0 . 4 9}$ & 0.00 & 0.06 & 0.01 & -0.02 \\
FP_F3 & $\mathbf{1 . 0 5}^{\star \star *}$ & $\mathbf{0 . 8 3}^{\star *}$ & 0.25 & 0.00 & -0.04 & 0.02 & $\mathbf{0 . 1 5}^{* *}$ \\
\hline
\end{tabular}

${ }^{*}$ Significance $<0.1 ;{ }^{* *}$ Significance $<0.05 ;{ }^{* * *}$ Significance $<0.01$

Regression equations:

$F P \_F 1=\beta_{0}+\beta_{1} I T+F 1+\beta_{2} L C \_F 1+\beta_{3} A+\beta_{4} G+\beta_{5} C+\beta_{6} S$

$F P \_F 3=\beta_{0}+\beta_{1} I T \_F 1+\beta_{2} L C \_F 1+\beta_{3} A+\beta_{4} G+\beta_{5} C+\beta_{6} S$ 


\section{References}

Ackerman, K. B. (1989), "Value-Added Warehousing Cuts Inventory Costs", Transportation \& Distribution, Vol. 30 (July), pp. 32-35.

Archer, N., Wang, S. and Kang, C. (2008), "Barriers to the adoption of online supply chain solutions in small and medium enterprises", Supply Chain Management: An International Journal, Vol. 13, No. 1, pp. 73-82.

Ashenbaum B., Maltz A.B. and Rabinovich E. (2005), "Studies of Trends in Third-Party Logistics Usage: What We Can Conclude?", Transportation Journal, Vol. 44, No. 3, pp. 3950 .

Barney, J.B. (1991), "Firm Resources and Sustained Competitive Advantage", Journal of Management, Vol. 17, No. 1, pp. 99-120.

Baron, R. M. and Kenny, D. A. (1986), “The Moderator-Mediator Variable Distinction in Social Psychological Research: Conceptual, strategic and statistical considerations", Journal of Personality and Social Psychology, Vol. 51, pp. 1173-1182.

Bowersox, D.J. and Daugherty, P.J. (1995), "Logistics Paradigms: the Impact of Information Technology", Journal of Business Logistics, Vol. 16, No. 1, pp. 65-80.

Bradley, P. (1994), “Contract Logistics: It's all about Costs”, Purchasing, Vol. 20 (October), No. 56, pp. 3-14.

Brown, J. S., Carr, G., Hagel, J. III, McFarlan, F.W., Nolan, R.L. and Strassmann, P. (2003), "Does IT Matter?: An HBR Debate", Harvard Business Review, June, pp. 1-17.

Calder, R. and Marr, P. (1998), “A Beef Producer Initiative in Traceability: Scottish Borders TAG”, Supply Chain Management: An International Journal, Vol. 3, No. 3, pp. 123-126.

Capgemini (2007), "Third-Party Logistics - The state of logistics outsourcing”, available at: www.3plstudy.com.

Cattell, R. B. (1966), "The Scree Test for the Number of Factors", Multivariate Behavioral Research, Vol. 1, No. 2, pp. 245-276.

Cho, J.J., Ozment, J. and Sink, H. (2008), "Logistics Capability, Logistics Outsourcing and Firm Performance in an E-Commerce Market", International Journal of Physical Distribution and Logistics Management, Vol. 38, No. 5, pp. 336-359.

Chopra, S. and Meindl, P. (2003), Supply chain management: Strategy, planning and operations, Prentice Hall, Upper Saddle River, New Jersey. 
Chow, H.K.H., Choy, K.L., Lee, W.B. and Chan, F.T.S. (2007), "Integration of Web-Based and RFID Technology in Visualizing Logistics Operations - a Case Study", Supply Chain Management: An International Journal, Vol. 12, No. 3, pp. 221-234.

Closs, D.J., Goldsby, T.J. and Clinton, S.R. (1996), "Information Technology Influences on World Class Logistics Capability", International Journal of Physical Distribution and Logistics Management, Vol. 27, No. 1, pp. 4-17.

Cooper M.C., Lambert D.M. and Pagh J.D. (1998), "What Should Be the Transportation Provider's Role in Supply Chain Management?" in Proceedings of the 8th World Conference on Transport Research, 12-17 July, Antwerp, Belgium.

Daugherty P.J., Sabath R.E. and Rogers D.S. (1992), "Competitive Advantage Through Customer Responsiveness", Logistics and Transportation Review, Vol. 28, No. 3, pp. 257272.

Delfmann, W., Albers, S. and Gehring, M. (2002), "The Impact of Electronic Commerce on Logistics Service Providers", International Journal of Physical Distribution \& Logistics Management, Vol. 32, No. 3, pp. 203-222.

Devaraj, S., Krajewski, L. and Wei, J. (2007), "Impact of eBusiness Technologies on Operational Performance: the Role of Production Information Integration in the Supply Chain", Journal of Operations Management, Vol. 25, No. 6, pp. 1199-1216.

e-Business Watch (2008), The European e-Business Report - The Impact of ICT and e-Business on Firms, Sectors and the Economy, 6th Synthesis Report of the Sectoral e-Business Watch, DG Enterprise \& Industry, European Commission.

European Commission (2005), The New SME Definition. User Guide and Model Declaration, DG Enterprise \& Industry, European Commission, Bruxelles.

Eurostat (2003), Panorama of Transport - Statistical overview of transport in the European Union, 1970-2001 - Part 2, Office for Official Publications of the European Communities, Luxembourg.

Evangelista P. and Sweeney E. (2006), "Technology Usage in the Supply Chain: the Case of Small 3PLs", The International Journal of Logistics Management, Vol. 17, No. 1, pp. 55-74. Fawcett, S.E., Stanley, L.L. and Smith, S.R. (1997), "Developing a Logistics Capability to Improve the Performance of International Operations", Journal of Business Logistics, Vol. 18, No. 2, pp. 101-127. 
Frazier, P. A., Tix, A. P. and Barron, K. E. (2004), "Testing Moderator and Mediator Effects in Counseling Psychology Research”, Journal of Counseling Psychology, Vol. 51, pp. 115-134. Giaglis, G.M., Minis, I., Tatarakis, A. and Zeimpekis, V. (2004), "Minimizing Logistics Risk through Real-Time Vehicle Routing and Mobile Technologies. Research to Date and Future Trends", International Journal of Physical Distribution \& Logistics Management, Vol. 34, No. 9, pp. 749-764.

Goode, S. and Stevens, K. (2000), "An Analysis of the Business Characteristics of Adopters and Non-Adopters of WWW", Technology Information and Management, Vol. 1, No. 1, pp. 129-154.

Gopal, G. and Cline, S. (2007), "Driving towards Sustainable Profitability: Transportation Service Providers and Customer Relationship Management”, Supply Chain Management: An International Journal, Vol. 12, No. 2, pp. 85-87.

Grant, R.M. (1991), "The Resource-Based Theory of Competitive Advantage: Implications for Strategy Formulation”, California Management Review, Spring, pp. 114-135.

Greene, W.H. (2008), Econometric Analysis, Prentice Hall, Upper Saddle River, New Jersey.

Gunasekaran, A. and Ngai, E.W.T. (2003), "The Successful Management of a Small Logistics Company”, International Journal of Physical Distribution and Logistics Management, Vol. 33, No. 9, pp. 825-842.

Gustin, C.M., Daugherty, P.J. and Stank, T.P. (1995), “The Effects of Information Availability on Logistics Integration”, Journal of Business Logistics, Vol. 16, No. 1, pp. 1-21.

Hair, J.F., Black, B., Babin, B., Anderson, R.E. and Tatham, R.L. (2005), Multivariate Data Analysis, $6^{\text {th }}$ ed., Prentice Hall, Upper Saddle River, New Jersey.

Hertz, S. and Alfredsson, M. (2003), "Strategic Development of Third Party Logistics Providers", Industrial Marketing Management, Vol. 32, No. 2, pp. 139-149.

Hong, E., Son, B. and Menachof, D., (2010), "Exploring the Link between IT Systems and Outsourcing of Logistics Activities: a Transaction Cost Perspective", International Journal of Logistics: Research and Applications, Vol. 13, No. 1, pp. 41-58.

James, L. R. and Brett, J. M. (1984), "Mediators, Moderators and Tests for Mediation", Journal of Applied Psychology, Vol. 69, pp. 307-321. 
James, M., Grosvenor, R. and Prickett, P. (2004), “e-Distribution: Internet-Based Management of a Merchandiser Supply Chain”, Supply Chain Management: An International Journal, Vol. 9, No. 1, pp. 7-15.

Jiang, B., Baker, R. and Frazier, G. (2009), “An Analysis of Job Dissatisfaction and Turnover to Reduce Global Supply Chain Risk: Evidence from China”, Journal of Operations Management, Vol. 27, No. 2, pp. 169-184.

Jin, B. (2006), "Performance Implications of Information Technology Implementation in an Apparel Supply Chain”, Supply Chain Management: An International Journal, Vol. 11, No. 4, pp. 309-316.

Kärkäinnnen, M. and Hölmstrom, J. (2002), "Wireless Product Identification: Enabler for Handling Efficiency, Customisation and Information Sharing", Supply Chain Management: An International Journal, Vol. 7, No. 4, pp. 242-252.

Kim, C., Yang, K.H. and Kim, J. (2008), “A Strategy for Third-Party Logistics Systems: A Case Analysis Using the Blue Ocean Strategy”, Omega, Vol. 36, No. 4, pp. 522-534.

Kim, S.W. (2006), "The Effect of Supply Chain Integration on the Alignment between Corporate Competitive Capability and Supply Chain Operational Capability", International Journal of Operations \& Production Management, Vol. 26, No. 10, pp. 1084-1110.

Kisperska-Moron, D. and Swierczek, A. (2008), "The Agile Capabilities of Polish Companies in the Supply Chain: An Empirical Study", International Journal of Production Economics, Vol. 118, No. 1, pp. 217-224.

Lai, K. (2004), "Service Capability and Performance of Logistics Service Providers", Transportation Research Part E, Vol. 40, No. 5, pp. 385-399.

Lai, F., Li, D., Wang, Q., and Zhao, X. (2008), “The Information Technology Capability of Third-Party Logistics Providers: A Resource-Based View and Empirical Evidence from China”, Journal of Supply Chain Management, Vol. 44, No. 3, pp. 22-38.

Lai, F., Zhao, X., and Wang, Q. (2006), "The Impact of Information Technology on the Competitive Advantage of Logistics Firms in China", Industrial Management \& Data Systems, Vol. 106, No. 9, pp. 1249-1271.

Larson, P. D., and Halldorsson, A. (2004), "Logistics versus Supply Chain Management: An International Survey”, International Journal of Logistics: Research and Applications, Vol. 7, No. 1, pp. 17-31. 
Lau, H.C.W., Lee, C.K.M., Ho, G.T.S. and Ip, W.H. (2006), "M-commerce to Support the Implementation of a Responsive Supply Chain Network", Supply Chain Management: An International Journal, Vol. 11, No. 2, pp. 169-178.

Leonida G. (2004), "L'importanza della Innovazione anche in Logistica", E by Logistics Conference, 28th May, Bologna, Confetra Research Centre, Bologna.

Lewis I. and Talalayevsky A. (2000), "Third-Party Logistics: Leveraging Information Technology”, Journal of Business Logistics, Vol. 21, No. 2, pp. 173-185.

Li, G., Yang, H., Sun, L. and Sohal, A. (2009), "The Impact of IT Implementation on Supply Chain Integration and Performance", International Journal of Production Economics, Vol. 120, No. 1, pp. 125-138.

Lin C.Y. and Jung C. (2006), "Influencing Factors on the Innovation in Logistics Technologies for Logistics Service Providers in Taiwan", Journal of American Academy of Business, Vol. 9, No. 2, pp. 257-264.

Lin, C. and Tseng, H. (2006), "Identifying the Pivotal Role of Participation Strategies and Information Technology Application for Supply Chain Excellence", Industrial Management \& Data Systems, Vol. 106, No. 5, pp. 739-756.

Lin, C. and Ho, Y. (2009), "RFID Technology Adoption and Supply Chain Performance: an Empirical Study in China's Logistics Industry", Supply Chain Management: An International Journal, Vol. 14, No. 5, pp. 369-378.

Liu, X., McKinnon, A.C., Grant, D.B. and Feng, Y. (2010), "Sources of Competitiveness for Logistics Service Providers: a UK Industry Perspective”, Logistics Research, Vol. 2, pp. 314.

Lu, C. and Yang, C. (2006), "Evaluating Key Logistics Capabilities for International Distribution Center Operators in Taiwan”, Transportation Journal, Vol. 45, No. 4, pp. 9-27.

Lynch, D.F., Keller, S.B. and Ozment, J. (2000), "The Effects of Logistics Capabilities and Strategy on Firm Performance", Journal of Business Logistics, Vol. 21, No. 2, pp. 47-67.

Mentzer, J.T. and Firman, J. (1994), "Logistics Control Systems in the 21st Century", Journal of Business Logistics, Vol. 15, No. 1, pp. 215-228.

Morash, E.A., Dröge, C.L.M. and Vickery, S.K. (1996), "Strategic Logistics Capabilities for Competitive Advantage and Firm Success", Journal of Business Logistics, Vol. 17, No. 1, pp. 1-22. 
Norek, C.D. and Langley Jr., J. (2007), "Leveraging Technology: A Strategy to Help 3PLs Add Value”, Logistics Quarterly, July, pp. 28-29.

Nunnally, J.C. and Bernstein, I.H. (1994), Psychometric theory, $3^{\text {rd }}$ ed., McGraw-Hill, New York.

O’Reilly, K. (2010), “3PL CEO Interviews - Strategies for Leading Your Company into the Recovery", Eye for Transport, available at: www.eft.com.

Ojala, L., Andersson, D. and Naula, T. (2006), "The Definition and Market Size of Third Party Logistics Services” In: Ojala, L. and Jamsa, P., eds. Third Party Logistics - Finnish and Swedish Experiences, Series Discussion and Working Papers n. 3, Turku: Turku School of Economics.

Ovalle, O.R. and Marquez, A.C. (2003), "The Effectiveness of Using E-Collaboration Tools in the Supply Chain: an Assessment Study with Systems Dynamics", Journal of Purchasing and Supply Management, Vol. 9, No. 4, pp. 151-163.

Olorunniwo, F.O. and Li, X. (2010), "Information Sharing and Collaboration Practices in Reverse Logistics", Supply Chain Management: An International Journal, Vol. 15, No. 6, pp. 454-462.

Paché, G. (1996), “L'entreprise en réseau entre mythes et réalités”, Gestion 2000 - Management et Prospective, Vol. 12 No. 1, pp. 33-50.

Panayides, P.M. (2004), "Logistics Service Providers: an Empirical Study of Marketing Strategies and Company Performance", International Journal of Logistics: Research and Applications, Vol. 7, No. 1, pp. 1-15.

Pearcy, D.H. and Giunipero, L.C. (2008), "Using E-Procurement Applications to Achieve Integration: What Role Does Firm Size Play?”, Supply Chain Management: An International Journal, Vol. 13, No. 1, pp. 26-34.

Piplani R., Pokharel S. and Tan A. (2004), "Perspectives on the Use of Information Technology at Third Party Logistics Service Providers in Singapore", Asia Pacific Journal of Marketing and Logistics, Vol. 16, No. 1, pp. 27-41

Poirier, C.C. and Bauer M.J. (2000), E-Supply Chain: Using the Internet to Revolutionize Your Business, Berrett-Koehler, San Francisco. 
Pokharel S. (2005), "Perception on Information and Communication Technology Perspectives in Logistics - A Study on Transportation and Warehouse Sectors in Singapore", The Journal of Enterprise Information Management, Vol. 18, No. 2, pp. 136-149.

Porter, M. E. (2001), "Strategy and the Internet”, Harvard Business Review, March, pp. 63-78.

Prahalad, C.K. and Hamel, G. (1989), "The Core Competence of Corporation", Harvard Business Review, May-June, pp. 79-91.

Prahalad, C.K. and Hamel, G. (1994), "Competing for the Future”, Harvard Business Review, July-August, pp. 122-128.

Prater, E. and Ghosh, S. (2006), "A Comparative Model of Firm Size and Global Operational Dynamics of U.S. Firms in Europe”, Journal of Operations Management, Vol. 24, No. 5, pp. $511-529$

Rabinovich, E., Windle, R., Dresner, M. and Corsi, T. (1998), "Outsourcing of Integrated Logistics Functions", International Journal of Physical Distribution \& Logistics Management, Vol. 29, No. 6, pp. 353-373.

Rai, A. Patnayakuni, R. and Seth, N. (2006), "Firm Performance Impacts of Digitally Enabled Supply Chain Integration Capabilities", MIS Quarterly, Vol. 30, No. 2, pp. 225-246.

Razzaque M.R. and Sheng C.C. (1998), "Outsourcing of Logistics Functions: a Literature Survey", International Journal of Physical Distribution \& Logistics Management, Vol. 28, No. 2, pp. 89-107.

Sanders, N. (2007), "An Empirical Study of the Impact of E-Business Technologies on Organizational Collaboration and Performance", Journal of Operations Management, Vol. 25, pp. 1332-1347.

Sanders, N. (2008), "Pattern of Information Technology Use: The Impact on Buyer-Suppler Coordination and Performance", Journal of Operations Management, Vol. 26, pp. 349-367. Sauvage, T. (2003), "The Relationship between Technology and Logistics Third-Party Providers", International Journal of Physical Distribution \& Logistics Management, Vol. 33, No. 3, pp. 236-253.

Selviaridis K. and Spring M. (2007), "Third Party Logistics: a Literature Review and Research Agenda", The International Journal of Logistics Management, Vol. 18, No. 1, pp. 125-150. Shang, K. and Marlow, P.B. (2005), "Logistics Capability and Performance in Taiwan's Major Manufacturing Firms", Transportation Research Part E, Vol. 41, pp. 217-234. 
Sharma, S. (2008), "Theory of Exchange", European Journal of Operational Research, Vol. 186, No. 1, pp. 128-136.

Sharma, S. (2010), "Policies Concerning Decisions Related to Quality Level", International Journal of Production Economics, Vol. 125, No. 1, pp. 146-152.

Sheehan N.T. and Foss N.J. (2007), "Enhancing the Prescriptiveness of the Resource-Based view through Porterian Activity Analysis”, Management Decision, Vol. 45, No. 3, pp. 450-461.

Sink, H. L., and Langley, C. (1997), "A Managerial Framework for the Acquisition of ThirdParty Logistics Services”, Journal of Business Logistics, Vol. 18, pp. 163-190.

Sum, C.C. and Teo, C.B. (1999), "Strategic Posture of Logistics Service Providers in Singapore", International Journal of Physical Distribution \& Logistics Management, Vol. 29, No. 9, pp. 588-605.

Tracey, M., Lim, J. and Vonderembse, A. (2005), “The impact of Supply-Chain Management Capabilities on Business Performance", Supply Chain Management: An International Journal, Vol. 10, No. 3, pp.179-191.

Vaidyanathan, G. (2005), “A Framework for Evaluating Third-Party Logistics", Communications of the ACM, Vol. 48, No. 1, pp. 89-94.

Van Hoek, R. (2001), "E-supply Chains-Virtually Non-Existing”, Supply Chain Management: An International Journal, Vol. 6, No. 1, pp. 21-28.

Van Hoek, R.I. and Chong, I. (2001), "Epilogue: UPS Logistics - Practical Approaches to the Esupply chain”, Supply Chain Management: An International Journal, Vol. 31, No. 6, pp. 463-468.

Van Hoek, R. (2002), "Using Information Technology to Leverage Transport and Logistics Service Operations in the Supply Chain: an Empirical Assessment of the Interrelation between Technology and Operations Management", International Journal of Information Technology and Management, Vol. 1, No. 1, pp. 115-130.

Van Laarhoven, P., Berglund, M., and Peters, M. (2000), “Third-Party Logistics in Europe-Five Years Later", International Journal of Physical Distribution and Logistics Management, Vol. 30, No. 5, pp. 425- 442.

Wang Q., Lai F. and Zhao, X. (2008), “The Impact of Information Technology in the Financial Performance of Third-Party Logistics Firms in China", Supply Chain Management: an International Journal, Vol. 13, No. 2, pp. 138-150. 
Ward, P. and Zhou, H. (2006), "Impact on Information Technology Integration and Lean/Just-InTime Practices on Lead-Time Performance”, Decision Sciences, Vol. 37, No. 2, pp. 177203.

Wright, B.D. and Linacre, J.M. (1989), Observations are always ordinal; measurements, however, must be interval, MESA Psychometric Laboratory, Chicago, IL.

Wu, F., Yeniyurt S., Kim, D. and Cavusgil, S.T. (2006), “The Impact of Information Technology on Supply Chain Capabilities and Firm Performance: A Resource-Based View", Industrial Marketing Management, Vol. 35, pp. 493-504.

Yusuf, Y.Y., Gunasekaran, A., Adeleye, E.O. and Sivayoganathan, K. (2004), "Agile Supply Chain Capabilities: Determinants of Competitive Objectives", European Journal of Operational Research, Vol. 159, pp. 379-392.

Zhao, M., Dröge, C. and Stank, T.P. (2001), “The Effects of Logistics Capabilities on Firm Performance: Customer-Focused versus Information-Focused Capabilities", Journal of Business Logistics, Vol. 22, No. 2, pp. 91-107. 